\title{
Novel 1,3,4-(thiadiazol-2-ylamino) methyl-5-(pyridin-4-yl)-1,3,4-oxadiazol-2-thiones: synthesis, docking and antimycobacterial testing
}

\author{
Trupti S. Chitre, Santosh Panda, Shital M. Patil, Aparna S. Chothe, G. Vignesh, \\ Amol B. Salake, Muthu K. Kathiravan*
}

Department of Pharmaceutical Chemistry, (PGwing), AISSMS College of Pharmacy, Maharashtra, India. Email: "drmkkathir@gmail.com

Received 17 May 2011; revised 2 June 2011; accepted 2 July 2011.

\begin{abstract}
In the present study, a novel series of Mannich bases of 3-substituted 5-(pyridin-4-yl)-1,3, 4-oxadiazol-2-thione derivatives were synthesized. Docking study was performed to rationalize the possible interactions between the synthesized compounds and active site of 14DM. The test compounds were screened for antimycobacterial activity using Middlebrook 7H9 medium against $M$. tuberculosis H37Rv (ATCC 27294) as well as Isoniazid (INH) resistant clinical strain. Among the series $5 c$ and $5 a$ are found to be most potent (susceptible) while the compound 5 fid not show activity against $M$. tuberculosis H37Rv (resistant). The SAR study reveals the importance of substitutions at para position for good activity.
\end{abstract}

Keywords: Mannich Base; Oxadiazole; Thiadiazole; Antimycobacterial; Docking

\section{INTRODUCTION}

Tuberculosis (TB) is a pandemic disease and its causative agent Mycobacterium tuberculosis is one of the most prolific infectious agents affecting humans. The 196 countries reporting to WHO in 2008 notified 5.6 million new and relapse cases in 2007, of which 2.6 million $(46 \%)$ were new smear-positive cases [1]. Furthermore, treatment of tuberculosis with human immuno deficiency virus infected patients (HIV) is difficult and results as the leading cause of death among HIV positive patients worldwide. Another factor which contributes to more number of deaths is the emergence of multiple drug resistance (MDR) [2-5].

1,3,4-Oxadiazoles and thiadiazoles have been reported as potent heterocyclic ring system with wide spectrum of biological activities [6-10]. Recently, 1,3,4-oxadiazole derivatives has been reported as antimycobacterial agents also [11]. The conversion of Isoniazid (INH) to Oxadiazoles produces the corresponding 5- substituted 3H-1,3,4-oxadiazol-2-thione, 3H-1,3,4,-oxadiazol-2-one and their 3-alkyl or aralkyl derivatives and is responsible for potent activity against $M$. tuberculosis strain H37Rv $[12,13]$. Foroumadi et al have reported a series of alkyl (5-(nitroaryl)-1,3,4-thiadiazole-2-ylthio) propionates as antimycobacterial agents [14]. The biologically active derivatives synthesized as mannich bases are reported to be physiologically important because of the altered solubility in aqueous solvents and has been used as antitubercular, antimalarial, vasorelaxing, anticancer and analgesic drugs [15-18].

Till now, no new drug has been introduced since the discovery of Rifampin in spite of major advances that have been made in the drug discovery process. Hence, there is an overwhelming need to develop novel antimycobacterial agents. Literature survey revealed that genomic DNA from the M. tuberculosis (MT) H37 Rvstrain, CYP 51-like gene encodes a bacterial sterol 14 $\alpha$-demethylase (MT P450 14DM), which acts on $14 \alpha$ -methyl sterols. Recently we have reported a series of novel 4-(morpholin-4-yl)-N'-(arylidene) benzohy-drazides as antimycobacterial agent [19]. In continuation of our project in development of new antimycobacterial agents, we thought of hybridizing the two potential pharmacophores i.e., 1,3,4-oxadiazole and thiadiazole which as such has been reported as antimycobacterial agents. Furthermore, solubility plays an important role for the development of drug in tuberculosis. Thus our aim was further refined to synthesize mannich base of these two pharmacophores and evaluate them for anti antimycobacterial activity. Herein we report the synthesis, docking and in vitro antimycobacterial activity of a 
series of mannich bases belonging to

5-(pyridine-4-yl)-1,3,4-oxadiazo 1-2-thiones. The docking study was performed to rationalize the possible interactions between the synthesized compounds and the active site of 14DM.

\section{EXPERIMENTAL}

\subsection{Chemistry}

The synthetic route used for the title compounds is outlined in Scheme 1. The thiosemicarbazones 2 were prepared by refluxing thiosemicarbazide and appropriate aromatic aldehydes 1 at $80^{\circ} \mathrm{C}$ for $4 \mathrm{hr}$. 2-amino 5-substituted 1,3,4-thiadiazole 3 were obtained by refluxing thiosemicarbazones $\mathbf{2}$ with ammonium ferric sulphate in water for $5 \mathrm{hrs}$. Oxadiazole-2-thione 4 was prepared according to the method reported in the literature using Isoniazid as starting material [13]. Mannich bases 5a-f were obtained by reacting 2-amino-5-substituted 1,3,4-thiadiazole and oxadiazole-2-thione in DMF with formamide for 2-3 $\mathrm{hr}$ [20-22].

\subsection{Modeling Studies}

\subsubsection{Molecular Docking Protocol}

All computations were carried out on a Wipro Intel Pentium processor with Windows XP Operating System. All the compounds were constructed using standard fragment library of Maestro 8.0 and geometry optimization was done by Macromodel program Schrödinger, LLC) using Optimized Potentials for Liquid Simulations-all atom (OPLS-AA) force field [23]. The molecular docking tool, GLIDE (Schrodinger Inc., USA) was used for ligand docking studies into the X-ray crystal structure of cytochrome P450 14 $\alpha$-sterol Demethylase (14DM) from Mycobacterium in complex with 4-phenylimidazole (PDB entry code 1E9X) [24] were downloaded from the RCSB Protein Data Bank (PDB). The protein structure was prepared for docking using 'protein preparation wizard' in Maestro wizard 8.0. The protein preparation uses the OPLS force field 23 for this purpose. Grids were defined by centering them on the ligand in the crystal structure using the $10 \AA$ box size. Ligprep 2.2 module utilized to produce the low energy conformer of ligands using MMFF94 force field [25]. The lower energy conformations of the ligands were selected and were docked into the grid generated from protein structures using standard precision (SP) docking mode [26].

\subsubsection{Docking and Scoring Functions}

The docking studies were performed for the designed compounds with 14DM enzyme and the results were compared with the natural ligand phenyl imidazole present within the receptor. The docked complexes of the designed compounds along with the ligand receptor poses have been shown in the Figure 1. The final evaluation is done with glide score (docking score) and single best pose is generated as the output for particular ligand.

$$
\begin{aligned}
\text { Gscore }= & \mathrm{a}^{*} \mathrm{vdw}+\mathrm{b}^{*} \text { cow }+ \text { Lipo }+\mathrm{H} \text { bond } \\
& + \text { Metal }+ \text { BuryP }+ \text { Rot } \mathrm{B}+\text { Site }
\end{aligned}
$$

where, vdW: Van der Waal energy; Coul: Coulomb energy; Lipo: lipophilic contact term; HBond: hydrogen-bonding term; Metal: metal-binding term; BuryP: penalty for buried polar groups; RotB: penalty for freezing rotatable bonds; Site: polar interactions at the active site; and the Coefficients of vdW and Coul are: $\mathrm{a}=0.065$, $\mathrm{b}=0.130$. If GScore was selected as the scoring function, a composite Emodel score is then used to rank the poses of each ligand and to select the poses to be reported to the user. Emodel combines GlideScore, the nonbonded interaction energy, and, for flexible docking, the excess internal energy of the generated ligand conformation.

\subsubsection{Antimycobacterial Activity}

All the newly synthesized mannich bases were assayed in vitro for antitubercular activity against $M$. tuberculosis H37Rv (ATCC 27294) and Isoniazid resistant strain. The anti-TB screening was carried out by using Middlebrook 7H9 medium [27,28].

\section{RESULTS}

\subsection{Modeling}

The docked complex of the designed compounds is shown in Figure 1. The designed compounds were found to display good binding affinity to the receptor. G-score, H-Bond Interaction and Contacts The more negative value of G-score indicates that the compound is more potent and good binding affinity (Table 1). The Standard (CoCrystalisedLigand) and Isoniazid have shown G-Score of -4.73 and -5.02 . The G-score of the designed compounds were found to be $\mathbf{5 c}>\mathbf{5 a}>$ Isoni azid $>\mathbf{5 b}>\mathbf{5 e}>$ standard co-crystallized ligand $>\mathbf{5 d}$. Besides the G-score, other parameters like energy and the E-model were also taken into consideration for the evaluation of the docking results; the values of the energy and E-model were found to be significantly more than that of the values of the standard co-crystallized ligand and Isoniazid. The designed compounds, $5 \mathbf{a}$ and 5d found to display 1 and 2 H- bonds with HIS 259 respectively. Standard (CoCrystalised Ligand) showed 1 H-Bond with HIS 259. It is well established and accepted fact that number of good van der Waals interactions decides the binding affinity for any ligand with receptor enzyme protein and bad, ugly contacts indicate steric clashes after docking which should be less for good activity. Therefore we have analyzed the binding 
<smiles>NNC(N)=S</smiles>

1

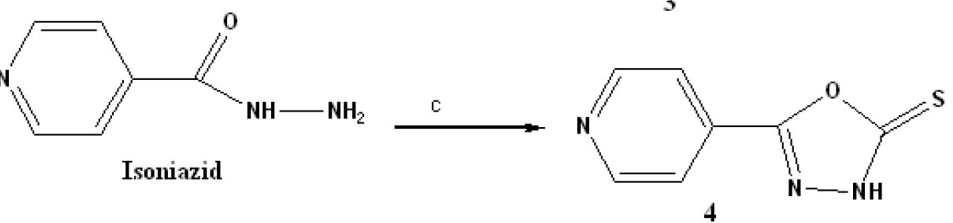

$3+4 \longrightarrow$

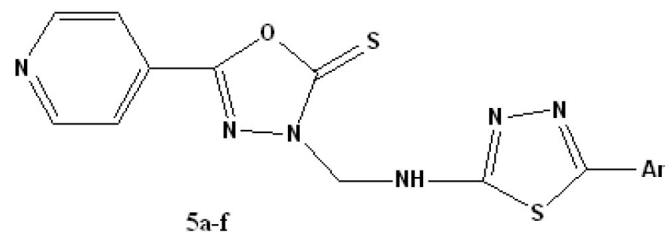

$5 \mathrm{a}-\mathrm{f}=\mathrm{Ar}=$
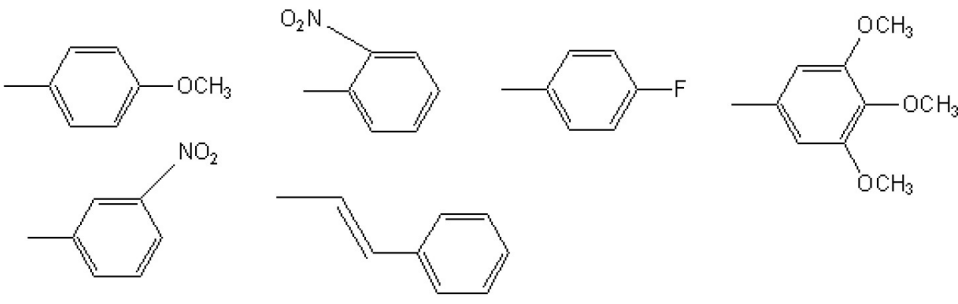

Scheme 1. Synthesis of 1,3,4-(thiadiazol-2-ylamino)methyl-5-(pyridine-4-yl)-1,3,4- oxadiazol-2-thione. Reagents and conditions (a) Ethanol, $\mathrm{HCl}$, Reflux (b) Ammonium ferric sulphate, $\mathrm{H}_{2} \mathrm{O}$, Reflux, (c) $\mathrm{CS}_{2}$, $\mathrm{KOH}$, (d) $\mathrm{CH}_{2} \mathrm{O}, 37 \%$.
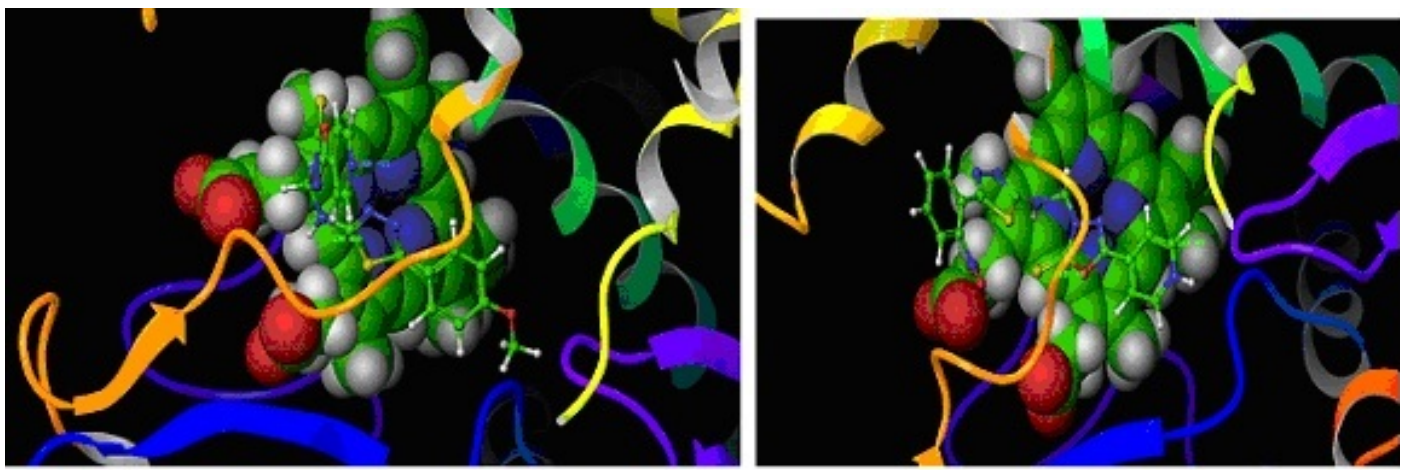

Figure 1. (a) Binding mode of $5 \mathrm{c}$ inside the pocket of crystal structure 14 demethylase; (b) Binding of 5a in 14 demethylase.

modes and abilities, considering the number of good, bad and ugly van der Waals (vdW) interactions of the standard and designed compounds with 14-DM active binding site.

\subsection{ADME Properties}

We have analyzed 44 physical descriptors and pharmaceutically relevant properties of mannich bases of 
3-substituted 5-(pyridine-4-yl)-1,3,4-oxadiazol-2-thione derivatives using Qikprop, among which significant descriptors are reported (Table 2) and are important for predicting the drug-like properties of molecules. These properties were:

1) Molecular weight (Mol_MW) (130 - 460)

2) Octanol/water partition coefficient ( $\log \mathrm{Po} / \mathrm{w})(-2$ 3.6)

3) Aqueous solubility (QPlogS) (-5.5 - 1)

4) Apparent MDCK cell permeability (QPPMDCK) $(<25$ poor, $>500$ great $)$

5) Brain/blood partition coefficient (QPlogBB) $(<-1.7)$

6) Percent human oral absorption (C80\% is high, $\mathrm{B} 25 \%$ is poor)

\subsection{Antimycobacterial Activity}

Amongst the compound tested 5c and 5a have shown good antimycobacterial activity (susceptible) against $M$. tuberculosis H37Rv (ATCC 27294) among the series. The effect of other test compounds on H37Rv and Isoniazid resistant strain is given in Table 3.

\section{DISCUSSION}

The results obtained reveals that the nature of substituents on the aromatic ring have a considerable impact on the antitubercular activities of the test compounds. Literature survey indicates that electrons-withdrawing groups amend lipophilicity of the test compounds, which in turn alters permeability across the mycobacterial cell membrane. Furthermore, the presence of electronegative atom such as fluoro in $\mathbf{5 c}$ has shown better activity than

5e and $\mathbf{5 b}$ which have nitro at ortho and meta position respectively, clearly indicating the importance of para positions for substitutions. Also 5a bearing a methoxy group at para position have shown good activity. Nitro group in spite of being electron withdrawing does not show significant biological response, revealing the importance of para substitution than ortho and meta. Complete lose of activity in $\mathbf{5 d}$ and $\mathbf{5 f}$ observed may be due to bulky less and steric factors. This is well supported by the docking studies performed, as more the $\mathrm{G}$ score of the test compounds better the activity and binding ability of molecule into the active site. Our docking indicates good van der Waals interaction than the standard with 14DM. Unlike antifungal azoles, it had shown just a stacking effect with Fe of 14DM and not binding with Fe.

\section{CONCLUSIONS}

In conclusion a series of mannich bases containing two pharmacophores were synthesized and characterized. Molecular docking studies were performed in $14 \mathrm{DM}$ protein docked with ligand to identify the possible inter- action. However two test compounds have shown better $\mathrm{G}$ score than Isoniazid. The test compounds were subjected to antimycobacterial study against $\mathrm{H} 37 \mathrm{Rv}$ and INH Resistant Clinical Strain. Larger G score better the binding affinity of test molecules and is reflected in antimycobacterial activity indicating a direct correlation between observed activity and energy score. This indicates that the designed series of mannich bases possessing electron withdrawing group at para position have shown antimycobacterial activity. So, these factors collectively indicate the importance, simplicity and wide applicability of designed series as antimycobacterial activity.

\section{SUPPLEMENTARY INFORMATION}

\section{(SI)}

Synthesis of 5-(pyridine-4-yl)-1,3,4-oxadiazole-2(3H)thione 4.

The compound, 5-(pyridine-4-yl)-1,3,4-oxadiazole$2(3 \mathrm{H})$-thione were prepared as per the reported procedure [13].

Synthesis of Thiosemicarbazones 2.

A mixture of appropriate aromatic aldehyde $1(1 \mathrm{~g}$, $8.06 \mathrm{mmol})$, thiosemicarbazide $(0.73 \mathrm{~g}, 8.06 \mathrm{mmol})$ and catalytic amount of $\mathrm{HCl}$ in $10 \mathrm{ml}$ ethanol were refluxed at $80^{\circ} \mathrm{C}$. The progress of the reaction was monitored by TLC. On completion, solvent were removed under vacuum. The solid obtained was recrystallized from 50\% aqueous ethanol.

Synthesis of 2-Amino thiadiazoles 3.

A mixture of thiosemicarbazone $2(1 \mathrm{~g}, 5.07 \mathrm{mmol})$ and ammonium ferric sulfate dodecahydrate $(0.1 \mathrm{~g})$ in $\mathrm{H}_{2} \mathrm{O}(5 \mathrm{ml})$ were refluxed for $1 \mathrm{~h}$. Then $1 \mathrm{~g}$ ammonium ferric sulfate in $\mathrm{H}_{2} \mathrm{O}(10 \mathrm{ml})$ were added and further continued for $5 \mathrm{hr}$. On completion of reaction, the mixture was chilled; the solid separated was filtered off, washed and crystallized from EtOH- $\mathrm{H}_{2} \mathrm{O}$.

Synthesis of Mannich bases 5a-f

General procedure for the synthesis of 1,3,4-thiadiazol-2-ylamino)methyl)-5-(pyridine-4-yl)-1,3 ,4-oxadiazole-2(3H)-thione.

Oxadiazole-2-thione $4(0.5 \mathrm{~g}, 2.79 \mathrm{mmol})$ and substituted 2-amino thiadiazoles $3(0.54 \mathrm{~g}, 2.79 \mathrm{mmol})$ were mixed in $15 \mathrm{ml}$ absolute ethanol and stirred. To the stirred suspension $(2.79 \mathrm{mmol}, 37 \%)$ formaldehyde was added drop wise and heated to reflux for $10-12 \mathrm{hrs}$. The progress of the reaction was monitored by TLC. On completion, reaction mixture was concentrated under reduced pressure and the residue obtained were recrysatllised from appropriate solvent.

Representative data from the series

3-((5-(4-methoxyphenyl)-1,3,4-thiadiazol-2-ylamino) methyl)-5-(pyridin-4-yl)-1,3,4-oxadiazole-2(3H)-thione 
Table 1. Results of molecular docking studies using standard precision mode of Glide.

\begin{tabular}{|c|c|c|c|c|c|c|c|c|}
\hline Sr. No & Title & G-score & E-Model & Energy & H-Bond & Good VDW & Bad VDW & $\begin{array}{l}\text { Ugly } \\
\text { VDW }\end{array}$ \\
\hline 1 & $5 c$ & -5.70 & -59.7 & -46.3 & 0 & 167 & 5 & 0 \\
\hline 2 & $5 a$ & -5.66 & -52.3 & -40.7 & 1 & 193 & 5 & 1 \\
\hline 3 & Isoniazid & -5.02 & -32.4 & -21.8 & 2 & 82 & 1 & 1 \\
\hline 4 & $5 b$ & -4.91 & -55.9 & -43.3 & 0 & 168 & 1 & 0 \\
\hline 5 & $5 e$ & -4.73 & -57.3 & -44.3 & 0 & 157 & 0 & 0 \\
\hline 6 & $\begin{array}{c}\text { Standard } \\
\text { (CoCrystalised } \\
\text { Ligand) }\end{array}$ & -4.73 & -34.3 & -21.6 & 1 & 119 & 1 & 0 \\
\hline 7 & $5 d$ & -4.60 & -55.0 & -42.7 & 2 & 170 & 0 & 0 \\
\hline 8 & $5 \mathrm{f}$ & -4.57 & -52.0 & -41.3 & 0 & 160 & 0 & 0 \\
\hline
\end{tabular}

Table 2. Prediction of ADME properties of designed derivatives using qikprop.

\begin{tabular}{ccccccc}
\hline Compd. no. & Mol_MW & $\log$ Po/w & $\log \mathrm{S}$ & $\log \mathrm{BB}$ & PMDCK & Human oral absorption (\%) \\
\hline $\mathbf{5 a}$ & 398.45 & 3.025 & -5.076 & -0.652 & 1191.76 & 96.55 \\
$\mathbf{5 b}$ & 413.42 & 2.397 & -4.856 & -1.379 & 209.62 & 80.46 \\
$\mathbf{5 d}$ & 458.50 & 2.226 & -5.253 & -0.802 & 1193.20 & 100 \\
$\mathbf{5 e}$ & 413.42 & 3.663 & -5.007 & -1.671 & 120.54 & 75.37 \\
$\mathbf{5 f}$ & 394.46 & -1.592 & -5.564 & -0.822 & 1266.35 & 100 \\
$\mathbf{5 c}$ & 386.42 & 3.195 & -5.342 & -0.477 & 2127.74 & 100 \\
Isoniazid & 137.14 & -0.646 & -0.052 & -0.843 & 123.74 & 66.89 \\
\hline
\end{tabular}

Higher the value of MDCK cell, higher the cell permeability. All designed compounds have shown the ADME properties in acceptable range.

\section{(5a)}

83\%, mp 243-245. ${ }^{1} \mathrm{H}$ NMR $\left(\mathrm{CDCl}_{3}\right) \delta(\mathrm{ppm}): 3.73$ (s, $\left.3 \mathrm{H}, \mathrm{OCH}_{3}\right), 4.0(\mathrm{~s}, 1 \mathrm{H}, \mathrm{NH}), 4.81\left(\mathrm{~s}, 2 \mathrm{H}, \mathrm{CH}_{2}\right), 7.21-7.65$ (m, 4H, phenyl), 7.73-7.85 (d, 2H, pyridyl), 8.12-8.31(d, 2H, pyridyl). MS (m/z \%) $398\left(\mathrm{M}^{+}\right), 399(\mathrm{M}+1)$. Anal. Calcd for $\mathrm{C}_{17} \mathrm{H}_{14} \mathrm{~N}_{6} \mathrm{O}_{2} \mathrm{~S}_{2}$ : C, 51.24; H, 3.54; N, 21.09; Found C, 51.41; H, 3.44; N, 21.11

3-((5-(4-fluorophenyl)-1,3,4-thiadiazol-2-ylamino)met hyl)-5-(pyridin-4-yl)-1,3,4-oxadiazole-2(3H)-thione (5c) 79.2\%, mp 257-259. ${ }^{1} \mathrm{H}$ NMR $\left(\mathrm{CDCl}_{3}\right) \delta(\mathrm{ppm}): 4.32(\mathrm{~s}$, $1 \mathrm{H}, \mathrm{NH}), 4.61\left(\mathrm{~s}, 2 \mathrm{H}, \mathrm{CH}_{2}\right), 7.17-7.44(\mathrm{~m}, 4 \mathrm{H}$, phenyl), 7.53 - 7.72 (d, 2H, pyridyn), 7.98 - 8.21(d, 2H, pyridyn). MS (m/z \%) $386\left(\mathrm{M}^{+}\right), 387(\mathrm{M}+1)$. Anal. Calcd for $\mathrm{C}_{16} \mathrm{H}_{11} \mathrm{FN}_{6} \mathrm{OS}_{2}: \mathrm{C}, 49.73 ; \mathrm{H}, 2.87 ; \mathrm{F}, 4.92 ; \mathrm{N}, 21.75 ; \mathrm{O}$, 4.14; S, 16.60; Found C, 49.63; H, 2.76; N, 21.69 3-((5-(3-nitrophenyl)-1,3,4-thiadiazol-2-ylamino)methyl )-5-(pyridin-4-yl)-1,3,4-oxadiazole-2(3H)-thione (5e) $82.8 \%$, mp $272-273^{\circ} \mathrm{C} .{ }^{1} \mathrm{H}$ NMR $\left(\mathrm{CDCl}_{3}\right) \delta(\mathrm{ppm})$ : $4.35(\mathrm{~s}, 1 \mathrm{H}, \mathrm{NH}), 4.58\left(\mathrm{~s}, 2 \mathrm{H}, \mathrm{CH}_{2}\right), 7.61-7.91(\mathrm{~m}, 4 \mathrm{H}$, phenyl), 7.96-8.12 (d, 2H, pyridin), 8.23-8.48 (d, 2H, pyridyn). MS (m/z\%) $413\left(\mathrm{M}^{+}\right), 414(\mathrm{M}+1)$. Anal. Calcd for $\mathrm{C}_{16} \mathrm{H}_{11} \mathrm{~N}_{7} \mathrm{O}_{3} \mathrm{~S}_{2}$ : C, 46.48; H, 2.68; N, 23.72; Found $\mathrm{C}$,
$46.53 ; \mathrm{H}, 2.84 ; \mathrm{N}, 23.79$

Anti-TB sensitivity test by Middlebrook 7H-9 broth (Macro)

The anti-TB screening was carried out by using Middlebrook $7 \mathrm{H} 9$ medium $[25,26]$ against $\mathrm{M}$. tuberculosis H37Rv (ATCC 27294). The basal medium was prepared, sterilized and to $4.5 \mathrm{ml}$ of this broth, $0.5 \mathrm{ml}$ of ADC (al-bumin-dextrose-catalase) supplement was added. Then a stock solution $(10 \mathrm{mg} / \mathrm{ml})$ of the test compounds was prepared and the final concentrations of 10,25 and $50 \mu \mathrm{g} / \mathrm{ml}$ were transferred to media bottles. Finally, 10 $\mu \mathrm{g}$ suspension of M. tuberculosis H37Rv strain $(100,000$ organisms $/ \mathrm{ml}$ adjusted by McFarland's turbidity standard) was transferred to each of the tubes and incubated at $37^{\circ} \mathrm{C}$ along with one growth control without compound and drug control was also set up. The bottles were observed for growth twice a week for a period of three weeks. The appearance of turbidity was considered as growth and indicates resistance to the compound. The growth was confirmed by making a smear from each bottle and performing a Zeil-Nelson stain at the end of 4 weeks. 
Table 3. Results of H37Rv and INH Resistant clinical strain testing.

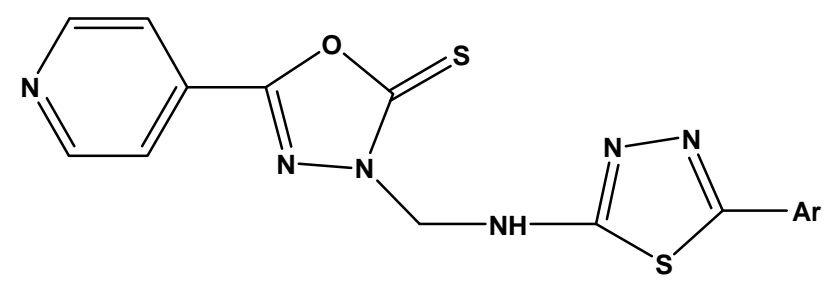

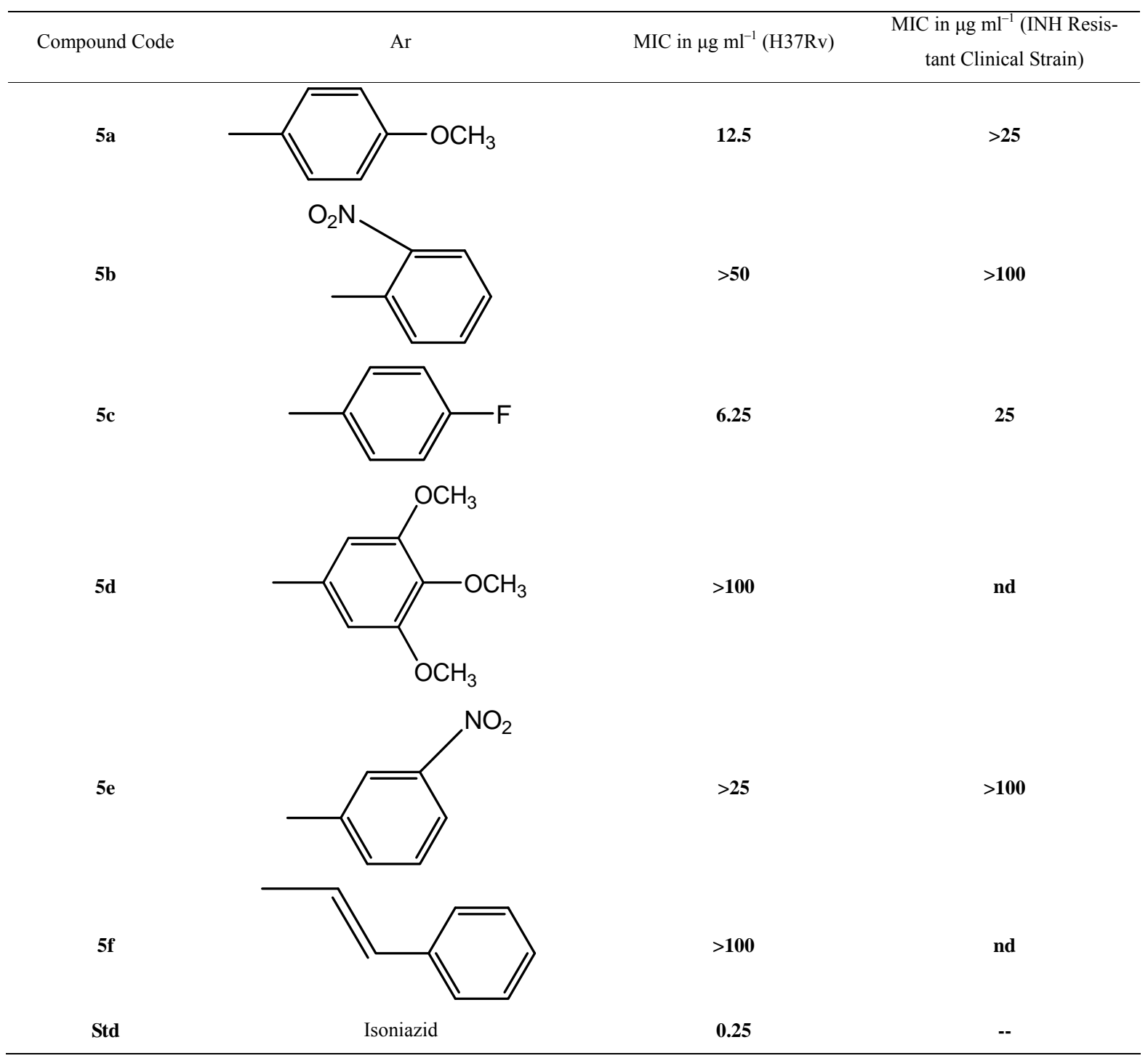

nd $=$ not determined

\section{ACKNOWLEDGMENTS}

We are grateful to Dr. Mrs. A. R. Madgulkar, Principal, AISSMS College of Pharmacy, Pune, for providing us with the necessary financial support and infrastructure for carrying out this work.

\section{REFERENCES}

[1] WHO. Tuberculosis. November 2010. http://www.who.int/mediacentre/factsheets/fs104/en/

[2] Dye, C., Williams, B., Espinal, M. and Raviglion, M. (2002) Erasing the world's slow stain: Strategies to beat multidrug-resistant tuberculosis. Science, 295, 20422046. doi:10.1126/science. 1063814

[3] Morris, S., Bai, G., Suffys, P., Portilo, L., Fairchok, M. and Rouse, D. (1995) Molecular Mechanisms of Multiple Drug Resistance in Clinical Isolates of Mycobacterium tuberculosis. Infectious Diseases, 171, 954-960. 


\section{doi:10.1093/infdis/171.4.954}

[4] Telzak, E., Sepkowitz, K., Alpert, P., Mannheimer, S., Mederd, F., El-Sadr, W., Blum, S., Gagliardi, A., Alomon, N. and Turett, G. (1995) Multidrug-Resistant Tu- berculosis in Patients without HIV Infection. The New England Journal of Medicineogy, 333, 907-912. doi:10.1056/NEJM199510053331404

[5] Basso, L. and Blanchard, J. S. (1998) Resistance to antitubercular drugs. Advances in Experimental Medicine and Biology, 456, 115-144.

doi:10.1007/978-1-4615-4897-3 7

[6] Navarrete-Vázquez, G., Molina-Salinas, G., Duarte- Fajardo Zetel, Z., Villarrea, J., Estrada-Soto, S., GonzálezSalazar, F., Hernández-Núñez, E., Fernendez, S. S. (2007) Synthesis and antimycobacterial activity of 4-(5-substituted-1,3,4-oxadiazol-2-yl)pyridines. Bioorganic \& Me-dicinal Chemistry, 5, 5502-5508. doi:10.1016/j.bmc.2007.05.053

[7] Shaban, M.A.E., Nasr, A.Z. and El-Badry, J. (1991) Synthesis and biological activities of some 1, 3, 4-oxadiazoles and bis (1,3,4-oxadiazoles). Journal of Islamic Academy of Sciences, 143, 184-186.

[8] Karakus, S. and Rollas, S. (2002) Synthesis and antituberculosis activity of new $N$-phenyl- $N^{\prime}$-[4-(5-alkyl/ arylamino-1,3,4-thiadiazole-2-yl)phenyl]thioureas. Farmaco, $57,577-581$ doi:10.1016/S0014-827X(02)01252-1

[9] Oruc, E., Rollas, S., Kandemirli, F., Shvets, N., Dimoglo, A. (2004) 1,3,4-Thiadiazole Derivatives. Synthesis, Structure Elucidation, and Structure-Antituberculosis Activity Relationship Investigation. Journal of Medicinal Chemistry, 47, 6760-6767.

[10] Nilufer, S., Sevim, R. (2006) Synthesis and antituberculosis activity of 2-(aryl/alkylamino)-5-(4-aminophenyl)1,3,4-thiadiazoles and their Schiff bases. Arkivoc, 12, 173-181.

[11] Macaev, F., Ghenadie, R., Serghei, P., Alexandru, G., Eugenia, S., Ludmila, V., Nathaly, S., Fatma, K., Anatholy, D. and Robert, R. (2005) Synthesis of novel 5-aryl-2-thio-1,3,4-oxadiazoles and the study of their structure-anti-mycobacterial activities. Bioorganic \& Medicinal Chemistry, 13, 4842-4850. doi:10.1016/j.bmc.2005.05.011

[12] Wilder-Smith, A.E. (1966) Some recently synthesised tuberculostatic 4-substituted oxadiazolones and oxadiazolthiones. Arzneimittelforschung, 16, 1034-1038.

[13] Mamolo, M., Zampieri, D., Vio, L., Fermeglia, M., Ferrone, M., Pricl, S., Scialino, G. and Banfi, E. (2005) Antimycobacterial activity of new 3-substituted 5-(pyridin-4-yl)-3H-1,3,4-oxadiazol-2-one and 2-thione derivatives. Preliminary molecular modeling investtigations. Bioorganic \& Medicinal Chemistry, 13, 3797-3809. doi:10.1016/j.bmc.2005.03.013

[14] Foroumadi, F., Mirzaei, M. and Shafiee, A. (2001) Antituberculosis agents II. Evaluation of in vitro antituberculosis activity and cytotoxicity of some 2-(1-methyl5-nitro-2-imidazolyl)-1,3,4-thiadiazole derivatives. Farmaco, 56, 621-623.

\section{doi:10.1016/S0014-827X(01)01099-0}

[15] Ali, M.S. and Shaharya, M. (2007) Oxadiazole mannich bases: Synthesis and antimycobacterial activity. Bioorganic \& Medicinal Chemistry Letters, 17, 3314- 3316. doi:10.1016/j.bmcl.2007.04.004

[16] a) Foroumadi, A., Kiani, Z., Soltani, F. (2003) Antituberculosis agents VIII: Synthesis and in vitro antimycobacterial activity of alkyl $\alpha$-[5-(5-nitro-2-thienyl)-1,3,4thiadiazole-2-ylthio]acetates. Farmaco, 58, 1073-1076. doi:10.1016/S0014-827X(03)00158-7 b)Foroumadi, A., Sakhteman, A., Sharifzadeh, Z., Mohammad, H., Hemmateenejad, B., Moshafi, M., Vosooghi, M., Amini, M.K. and Shafiee, A. (2007) Synthesis, antituberculosis activity and QSAR study of some novel 2-(nitroaryl)5-(nitrobenzylsulfinyl and sulfonyl)-1,3,4-thiadiazole derivatives. DARU Journal of Pharmaceutical Sciences, 15, 218-226.

[17] Foroumadi, A., Zahra, K. (2006) Synthesis and antimycobacterial activity of some alkyl [5-(nitroaryl)-1,3,4thiadiazol-2-ylthio]propionates. Bioorganic \& Medicinal Chemistry Letters, 16, 1164-1167. doi:10.1016/j.bmcl.2005.11.087

[18] Karthikeyan, M., Prasad, D.J., Boja, P., Bhat, S., Bantwal, S. and Nalilu, S. (2006) Synthesis and biological activity of Schiff and Mannich bases bearing 2,4-dichloro5-fluorophenyl moiety. Bioorganic \& Medicinal Chemistry, 14, 7482-7489. doi:10.1016/j.bmc.2006.07.015

[19] Raparti, V., Chitre, T., Bothara, K.G., Kumar, V., Dangre, S., Khachane, C., Gore, S., Deshmane, B. (2009) Novel 4-(morpholin-4-yl)-N'-(arylidene)benzohydrazides: Synthesis, antimycobacterial activity and QSAR invest- tigations. European Journal of Medicinal Chemistry, 44, 3954-3960. doi:10.1016/j.ejmech.2009.04.023

[20] Sriram, D., Yogeeswari, P. and Reddy, S. (2008) Antimycobacterial activities of novel 2-(sub)-3-fluoro/nitro5,12-dihydro-5-oxobenzothizolo[3,2-a]quinoline-6-carbo xylic acid. Bioorganic \& Medicinal Chemistry, 16, 34083418. doi:10.1016/j.bmc.2007.11.016

[21] Joshi, S. and Khosla, N. (2004) In vitro study of some medicinally important Mannich bases derived from antitubercular agent. Bioorganic \& Medicinal Chemistry, 12, 571-576. doi:10.1016/j.bmc.2003.11.001

[22] Singh, I.P., Saxena, A.K., Shankar, K. (1986) Synthesis and anti-inflammatory activity of oxadiazoline thione hydrochlorides. European Journal of Medicinal Chemistry: Chimica Therapeutica, 21, 267-269.

[23] Jorgensen, W., Maxwell, D., Tirado-Rives, J. (1996) Development and Testing of the OPLS All-Atom Force Field on Conformational Energetics and Properties of Organic Liquids. Journal of American Chemical Society, 118, 11225-11236. doi:10.1021/ja9621760

[24] Podust, L., Poulos, T., Waterman, M. (2001) Crystal structure of cytochrome P450 $14 \alpha$-sterol demethylase (CYP51) from Mycobacterium tuberculosis in complex with azole inhibitors. Proceedings of the National Academy of Sciences of U.S.A, 98, 3068-3073. doi:10.1073/pnas.061562898

[25] Hayes, M. J., Stein, M. and Weiser, J. (2004) Accurate 
Calculations of Ligand Binding Free Energies: Chiral Separation with Enantioselective Receptors. The Journal of Physical Chemistry, 108, 3572-3580.

[26] Friesner, R. A.; Murphy, R. B.; Repasky, M. P.; Frye, L. L.; Greenwood, J. R.; Halgren, T. A.; Sanschagrin, P. C.; Mainz, D. T. (2006) Extra Precision Glide: Docking and Scoring Incorporating a Model of Hydrophobic Enclosure for Protein-Ligand Complexes. Journal of Medicinal Chemistry, 49, 6177. doi:10.1021/jm0512560
[27] Elmer, W.K., Stephen, D.A., William, M.J., Paul, C.S. and Washing, C.W. (2002) Text book of Diagnostic Microbiology 5 Lippincot-Pub, J. B. Lippincott Co., Philadelphia, p. 125.

[28] Goto, S., Jo, K., Kawakita, T., Kosakai, N., Mitsuhashi, S., Nishino, T., Ohsawa, N., Tanami, H. (1981) Determination method of minimum inhibitory concentrations. Chemotherapy, 29, 76-79. 